\title{
The Role of Information Accuracy and Outcome Transparency on Forced Distri- bution Rating System (FDRS) Bias: An Experimental Study
}

\author{
Fuadhillah Kirana Putri* \\ Faculty of Economics and Business, Universitas Gadjah Mada, Indonesia
}

*Corresponding author:

E-mail: putri.kirana2020@gmail.com

\begin{abstract}
Forced Distribution Rating System (FDRS) is a performance appraisal system that forces supervisors to distribute employee rating results according to predetermined categories. FDRS aims to distinguish high, average, and low-performing employees so that low-performing employees can be identified. In practice, the supervisor experiences problems in assessing low-performing employees because the supervisor often does not have any data about these employees, so that bias cannot be avoided. By using the Equity Theory and Social Comparison Theory, this study aims to test empirically the role of information accuracy and outcome transparency as control systems in minimizing bias in FDRS. This study used a web-based experimental method with a $2 \times 2$ design between subjects with two information accuracy treatments (high and low) and two outcome transparency treatments (high and low). The results showed that high information accuracy affects the supervisor's intentions to avoid bias in FDRS. The results also indicate that the high outcome transparency strengthens the supervisor's intentions to avoid bias in FDRS when the information accuracy is relatively high. The highest tendency for a supervisor to do bias in FDRS is in a condition when there is low information accuracy with a high level of outcome transparency
\end{abstract}

Keywords: Information accuracy, outcome transparency, performance measurement, forced distribution rating system

\section{Introduction}

This study aims to test empirically information accuracy and outcome transparency as control systems against the bias of subjective performance appraisal, Forced Distribution Rating System (FDRS). This study will focus on the tendency of managers to overestimate the rankings of employees who are underperforming which is called leniency bias. The existence of leniency bias is caused by assessors who are too kind and reluctant to use a lower spectrum because they usually cannot differentiate between high and low- performing employees so that ratings tend to be raised relative to the distribution of actual performance results (Berger et al., 2013). In subjective performance appraisal, middle managers act as appraisers and they have a high possibility to do bias because they consider their incentives in the performance evaluation process. The managers' incentive depends on the design of the control system because the control system has an impact on the costs and benefits associated with making evaluation decisions. Therefore, organizations can influence manager behavior in providing ratings by creating and providing specific control systems and increasing the effectiveness of the subjective performance appraisal evaluation process (Bol et al., 2016).

$77 \%$ of firms believe that leniency bias endangers the legitimacy of the organization's performance appraisal system (Bretz et al., 1992). The design of the information accuracy control system and the outcome transparency have been used by Bol et al. (2016) as an effort to minimize bias in subjective performance appraisals. The results showed that leniency bias can be minimized by implementing information accuracy and high outcome transparency. Bol et al. (2016) then suggested further research to

\footnotetext{
How to cite:
}

Putri, F. K. (2021). The role of information accuracy and outcome transparency on Forced Distribu-tion Rating System (FDRS) bias: An experimental study. $1^{\text {st }}$ ICEMAC 2020: International Conference on Economics, Management, and Accounting. NST Proceedings. pages 81-89. doi: 10.11594/ nstp.2021.1009 
use information accuracy and outcome transparency in the Forced Distribution Rating System (FDRS). This performance appraisal forces the raters to avoid possible leniency (Scullen et al., 2005).

Jack Welch, the former CEO of General Electric (GE), pioneered FDRS in America. GE uses a 20/70/10 FDRS distribution where 20\% is for higher performers, $70 \%$ for average performers, and $10 \%$ for lower performers. He believes that this approach is the key to organizational competitive advantage, especially since it can periodically clear the "deadwood" (i.e. employees who fall in the lowest performance category are terminated) and can motivate those who are left (Bates, 2003; Stewart et al., 2010). Thus, FDRS can be an effective way in increasing the average potential workforce in organizations (Scullen et al., 2005). This is confirmed by Berger et al. (2013) in their successful research that showed that the implementation of FDRS can increase employee performance productivity by $8 \%$.

Although FDRS has several positive sides for companies, the implementation of FDRS cannot be separated from the obstacles. The application of FDRS is considered more difficult to be implemented because middle managers sometimes do not have information about the employees they are assessing while middle managers are required to rate employees with the worst performance categories (Schleicher et al., 2009). In practice, low-performing employees in high-performing groups are often better than high-performing employees in average-performing groups (Chattopadhayay \& Ghosh, 2012). Thus, in performance appraisal, it is necessary to have control systems.

This study follows up on suggestions from Bol et al. (2016) to use control system designs as an effort to minimize the presence of leniency bias in FDRS. Consistent with the hypotheses, the results showed that high information accuracy affected managers' intentions to avoid bias in FDRS. The results also indicate that the existence of high outcome transparency strengthens managers' intentions in avoiding bias in evaluating FDRS performance when information accuracy is relatively high.I

This research has several theoretical and practical contributions. In terms of the management control system literature, this study contributes to adding and broadening insights on how the effect of information accuracy is moderated by outcome transparency on FDRS setting. Little previous research has discussed efforts to minimize performance appraisal bias (Giebe \& Gürtler, 2012; Golman \& Bhatia, 2012). Also, this study adds to the literature regarding the application of FDRS in the rater perspective because the previous study is still lack in discussing it (Schleicher et al., 2009).

In practical terms, this research can be an input for the practical world to consider the existence of information accuracy and outcome transparency as control systems in implementing FDRS. The organization can increase the information accuracy so that middle managers can use that information as the basic consideration in assessing the employees when the organization implements FDRS. The results of this study indicate that the existence of transparency of results can reduce the existence of bias in FDRS so that companies should apply high outcome transparency about the result of FDRS because not all organizations apply this policy.

\section{Literature Review}

Previous research on FDRS has been carried out, for example, Scullen et al. (2005) show that FDRS can increase labor potential depending on the percentage of voluntary turnover and low-performing workers will be fired. Blume et al. (2013) and Malhotra \& Mukherjee (2013) examined whom FDRS is suitable to be implemented. Blume et al. (2013) showed that individuals who have higher cognitive consider the application of FDRS to be fair. Meanwhile, Blume et al. (2013) and Malhotra \& Mukherjee (2013) showed that junior employees are more interested in implementing FDRS compared to senior employees who consider absolute rank better than FDRS.

From several previous studies, middle managers face some difficulties when FDRS is implemented. The information used by middle managers for assessing is often not quite informative (Schleicher et al., 2009). Also, employees perceive FDRS to be unfair (Moon et al., 2016; Schleicher et al., 2009) especially when there is an error implementation (Chattopadhayay \& Ghosh, 2012). FDRS can increase the potential for employee performance in certain years (Scullen et al., 2005) but not increase the potential for long-term employee performance (Mulligan \& Bull Schaefer, 2011).

Although Schleicher et al. (2009) stated that FDRS was perceived as unfair by employees, on the other hand, Blume et al. (2013) show that FDRS is perceived as fairer and more attractive to employees 
with high cognitive levels. This is reinforced by the research of Moon et al. (2016) state that FDRS can motivate efforts and help attract and retain high-skilled employees.

\section{Hypothesis}

The managerial accounting system has an important role for organizations. The information generated from these systems can be used in planning and decision-making and can motivate each individual in the organization (Zimmerman, 2000). This information system can provide employees with information about their performance in comparison to others. Managers who receive information about the performance level of coworkers will use this information to update their beliefs about coworkers' intentions and behavior (Christian, 2018). If the information contained in the management accounting system is open and accurate, of course, managers will find it easier to provide subjective assessments. Open information facilitates communication, information sharing, and collaboration (Evans et al., 2012).

Schleicher et al. (2009) conducted interviews with managers who used FDRS and stated that the problem that often arises in FDRS is that the performance appraisal among employees does not always match the categories contained in FDRS. For example, sometimes middle managers are forced to identify employees who are performing poorly even though the middle managers do not have data on these employees (Bates, 2003). This makes the rater feel difficult and feels unfair with FDRS because it forces them to assess employee performance into certain categories that may not reflect their real performance (Schleicher et al., 2009). In this condition, managers will tend to carry out a leniency bias because managers care about the performance of their employees. This is because by giving a higher rating than it should be, managers can increase short and/or long-term compensation and minimize personal costs associated with the evaluation process. These costs are caused by a lack of accuracy of the information that encourages managers to carry out investigations, discussions, or test work documents so that it requires personal costs and takes a lot of time (Maas et al., 2012).

Also, the cost of confrontation can arise if an employee appeals because he feels unfair to the results of the assessment obtained. According to Social Comparison Theory (Festinger, 1954), individuals have the urge to compare themselves with others concerning their abilities. Employees rely on performance as a proxy for ability because the ability is often unobserved. Each employee rated their ability in social comparisons based on relative performance.

After comparing the results of performance appraisals, a sense of employee injustice may arise. This sense of injustice can be explained by Equity Theory which explains that employees respond negatively to disproportionate input and output ratios. Input is the employee's contribution to work, such as the quantity and quality of goods or services produced, work experience, and effort expended. While output (outcome) refers to what people get from their work, such as salary, additional benefits, granting of status, or any other kind of reward that is intrinsic to the job itself (Adams, 1964). Therefore, managers will tend to exercise a leniency bias to avoid spending personal costs and confrontation costs by carrying out a leniency bias. Thus, if the relatively low accuracy of information is used as a basis for evaluation by managers, the tendency of managers to carry out leniency bias will be higher (Bol, 2011; Harris, 1994; Maas et al., 2012).

H1: The tendency of middle managers to avoid FDRS bias is higher when middle managers obtain relatively high information accuracy than when middle managers obtain relatively low information accuracy.

Bol et al. (2016) argued that the effect of information accuracy on the existence of a leniency bias depends on the level of outcome transparency so that the tendency of managers to carry out leniency bias in performance ratings is only reduced by increasing the accuracy of information if there is relatively high outcome transparency. This can happen because, in high outcome transparency, employees can compare the results of performance appraisals with other employees. Following the Social Comparison Theory (Festinger, 1954), which in the context of FDRS performance appraisal, individuals will compare the results of employee ratings with other employees. Employees will compare whether the performance between one another employee is following the rating they received.

When outcome transparency is low, employees cannot observe each other's ratings and awards. Therefore, middle managers can reduce their costs by giving higher-than-true rankings according to their 
self-perception. If the managers do this when the outcome transparency is high, employees may feel dissatisfied or losing motivation. This is even more so if, in the FDRS assessment, the managers give the low-performing employee into the high-performing employee category so that the employee will automatically get a high ranking too. High-performing employees will feel their performance is relatively undervalued when low-performing employees get a higher rating than they should. Thus, this can create a sense of injustice between employees. Following the Equity Theory (Adams, 1964), truly high-performing employees will respond negatively to low-performing employees who have high rankings and have the potential to get promotion opportunities or bonuses. High-performing employees with low ratings can even confront by filing a formal appeal against the unfairness of the judge's decision.

Thus, when outcome transparency is high, the existence of a leniency bias creates additional personal costs for middle managers. Middle managers are likely to only increase the level of differentiation when the additional benefit is to motivate high performers rather than lower performers. As information accuracy increases, it is less expensive to confront low-rank employees with lowperforming employees, whereas high-performing employees will tend to be less forgiving about ranking distribution with relatively little variance. As a result, managers' cost and benefit trade-offs will lead them to differentiate more when information accuracy increases when outcome transparency is high (Bol et al., 2016).

Keep in mind that the primary purpose of a performance appraisal system is to foster organizational and individual growth, which means higher performance as a benchmark every time. For higher comparisons, the FDRS method is very precise. Most importantly, the objectives and procedures involved in FDRS must be communicated properly and accurately to all people who are part of the system (Malhotra \& Mukherjee, 2013).

Hypothesis 2: Higher outcome transparency reinforces managers' tendency to avoid FDRS bias when information accuracy is relatively high

\section{Methodology}

\section{Research strategy}

The unit of analysis in this research is an organization that implies a population of all organizations. However, this study will focus on retail companies. The unit of analysis is what or who is tested to create a summary description of all units and to explain the differences between them (Babbie, 2007).

\section{Experimental procedure}

The web-based experiment was started by distributing the link www.risetmsiugm.cart-erin.-com to each respondent. The start page of the web is the participant consent sheet to participate in the experiment. Participants who are willing to take part in the experiment will be asked to register by filling in their e-mail, telephone number, and password. Furthermore, participants will log in by entering their email and password.

In this study, participants acted as the regional manager of the PRAMADANA Yogyakarta Department Store whose task was to provide a performance appraisal in the form of ratings to five store managers. PRAMADANA Department Store is a profit center that implements FDRS.

Participants are forced to give different ratings to each store manager according to the category. By using this scoring system, store managers who perform very well and very badly can be identified, so that companies can find out which store managers will receive rewards in the form of promotion and punishment in the form of changing store managers.

Participants will be exposed to high or low information accuracy treatment and high or low outcome transparency. Also, participants will receive information about the performance indicators of stores A, B, C, D, and E. Information on these indicators includes sales, profit, customer satisfaction levels, and average employee satisfaction levels. Participants then gave ratings to each store manager by considering the treatment and performance indicators that had been received.

Furthermore, participants will be faced with questions related to the intention to manipulate in giving FDRS ratings. The intended manipulation is to assign an inappropriate rating to the store manager, 
for example giving Store Manager A, which should have been rated 1 (best) to rank 4 (poor). This manipulation occurs because each participant will receive a different treatment.

This study uses a manipulation check which aims to determine whether the participants understand and can interpret the treatment they have received (Nahartyo, 2013). At the end of the assignment, participants are asked to provide demographic information including gender, age, university origin, semester, last GPA, and courses taken (Management Accounting and Ac-counting Control Systems).

\section{Data analysis}

The descriptive analysis used in this study is the minimum, maximum, mean, and standard deviation of the participants. This research uses ANOVA to test the hypotheses and the data is proceed using SPSS 25 .

\section{Results and Discussion}

Hypothesis 1 states that managers will more avoid bias in evaluating FDRS performance when there is information accuracy. In particular, the tendency of middle managers to avoid FDRS bias is higher when obtaining relatively high information accuracy than when managers obtain relatively low information accuracy. H1 is significantly supported based on the results of the Two- Ways ANOVA test (Table 1), which shows the value of $\mathrm{p}=0.045<0.05$.

Furthermore, the comparison of the average value of the FDRS bias (Table 2) is shown to be smaller in conditions where there is high information accuracy (mean $=1.72)$ than when the information

Accuracy is low (mean $=2.35$ ). This shows that there is a difference in the tendency of managers to do bias in FDRS when there is high and low information accuracy so that hypothesis 1 is supported.

Hypothesis 2 stated that higher outcome transparency strengthens managers' intentions to avoid bias in evaluating FDRS performance when information accuracy is relatively high. This hypothesis was significantly supported after going through the One-Way ANOVA test which can be seen in Table 3 with a value of $p=0.007<0.05$. The test results indicate that managers tend to avoid the FDRS bias when there is high information accuracy and when the company implements a high transparency policy than when the company implements low outcome transparency. This is also following the results of the interaction test which can be seen in Figure 1. This graph shows that the manager's intention to bias the FDRS assessment is lowest when there is high information accuracy and high outcome transparency. Thus, hypothesis 2 is supported.

Table 1. Result of two-ways ANOVA

\begin{tabular}{ccccc}
\hline Source & df & $\begin{array}{c}\text { Mean } \\
\text { Square }\end{array}$ & F & Sig. \\
\hline Information Accuracy & 1 & 4,410 & 4,225 & 0,045 \\
Outcome Transparency & 1 & 1,643 & 1,575 & 0,216 \\
Information Accuracy* & 1 & 5,446 & 5,218 & 0,027 \\
Outcome Transparency & & & & \\
Error & 48 & 1,044 & & \\
\hline
\end{tabular}




\begin{tabular}{|c|c|c|c|}
\hline \multirow[t]{2}{*}{ Information Accuracy } & \multicolumn{2}{|c|}{ Outcome Transparency } & \multirow{2}{*}{ Total } \\
\hline & High & Low & \\
\hline High & $\begin{array}{c}\text { Sel 1: } \\
N=17 \\
x=1,24 \\
\mathrm{SD}=0,437\end{array}$ & $\begin{array}{c}\text { Sel 2: } \\
N=15 \\
x=2,27 \\
S D=1,387\end{array}$ & $\begin{array}{c}\mathrm{N}=32 \\
\mathrm{x}=1,72 \\
\mathrm{SD}=1,114\end{array}$ \\
\hline Low & $\begin{array}{c}\text { Sel 3: } \\
N=10 \\
X=2,50 \\
S D=0,707\end{array}$ & $\begin{array}{c}\text { Sel 4: } \\
\mathrm{N}=10 \\
\mathrm{X}=2,20 \\
\mathrm{SD}=1,317\end{array}$ & $\begin{array}{c}\mathrm{N}=20 \\
\mathrm{x}=2,35 \\
\mathrm{SD}=1,040\end{array}$ \\
\hline Total & $\begin{array}{c}\mathrm{N}=27 \\
\mathrm{x}=1,70 \\
\mathrm{SD}=0,823\end{array}$ & $\begin{array}{c}\mathrm{N}=25 \\
\mathrm{x}=2,24 \\
\mathrm{SD}=1,332\end{array}$ & $\begin{array}{c}\mathrm{N}=52 \\
\mathrm{x}=1,96 \\
\mathrm{SD}=1,120\end{array}$ \\
\hline
\end{tabular}

Table 3. Result of One-Way ANOVA

\begin{tabular}{lllll}
\hline & df & Mean Square & F & Sig. \\
\hline Between Groups & 1 & 8.477 & 8.479 & 0.007 \\
Within Groups & 30 & 1.000 & & \\
Total & 31 & & & \\
\hline
\end{tabular}

\section{Additional analysis}

Based on Figure 1, the interaction chart of information accuracy and outcome transparency, the highest intention of managers to do bias in FDRS is in a condition when there is low information accuracy with a high level of transparency (mean $=2.50$ ).

Managers will consider the personal cost and benefit trade-offs when information accuracy is low. This is because to explore more information about store manager performance, area managers need to carry out investigations, discussions, or test work documents that require more cost and take a lot of time (Maas et al., 2012).

Managers are likely to increase differentiation when they perceive the added benefit of motivating high-performing employees over low- performing employees. This is because the main purpose of FDRS is to motivate efforts and help attract and retain high-skilled employees (Moon et al., 2016). Thus, if there is a confrontation between a regional manager and a low-performing store manager, the costs incurred will be cheaper than when confronting high-performing employees (Bol et al., 2016).

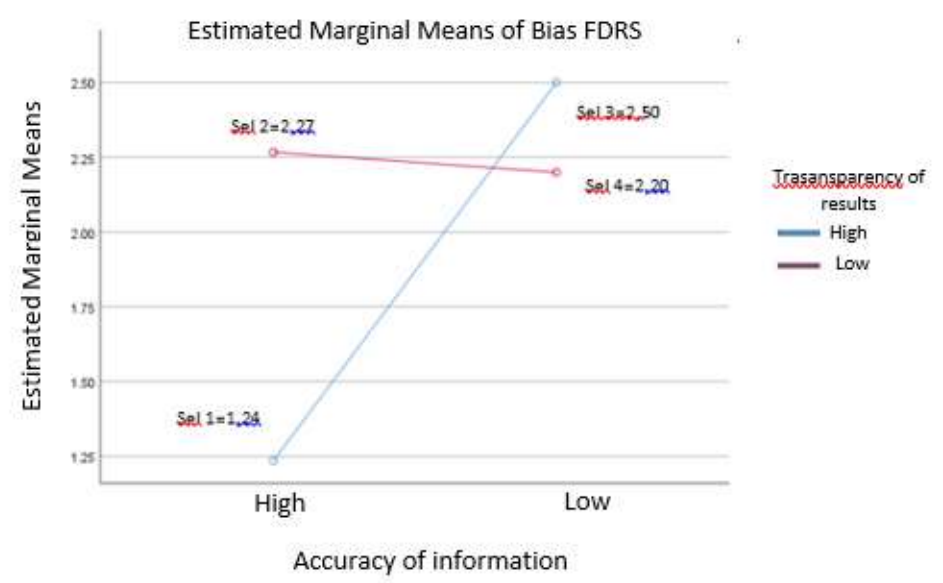

Figure 1. Interaction graph of information accuracy and outcome transparency 
The support for hypothesis 1 is in line with Christian's (2018) statement which states that when managers receive information about coworkers' performance levels, they will use this information to update their beliefs about coworkers' intentions and behavior, especially in terms of performance appraisals. In addition, the accuracy of the information can help in dealing with FDRS problems, namely performance appraisals among employees who do not always match the categories contained in the FDRS because the appraiser is forced to identify poorly performing employees even though the appraiser does not have data about these employees (Bates, 2003). With accurate information, managers will feel fair even though they are forced to judge their employees poorly for making an assessment based on the accuracy of the information they received.

The support for hypothesis 2 is in line with research Bol et al. (2016) which argues that the effect of information accuracy to avoid performance appraisal bias can be maximized by increasing the outcome transparency. This can happen because, in high outcome transparency, employees can compare their appraisal results with their coworkers. According to Social Comparison Theory (Festinger, 1954), individuals have the urge to compare themselves with others concerning their performance results. In conditions of high outcome transparency, when store managers compare the results of the evaluation, the confrontation between regional managers and store managers will also be minimized because the accuracy of store manager information on which the evaluation is based is relatively high.

\section{Conclusion}

Based on the analysis, it can be concluded that the high accuracy of information affects the manager's intention to avoid bias in FDRS. The lowest tendency of managers to do FDRS bias is when there is high information accuracy compared to when there is low information accuracy. Then, the high outcome transparency reinforces the intention of managers to avoid bias in evaluating FDRS performance when the accuracy of the information is relatively high. Managers tend to avoid the FDRS assessment bias when there is high information accuracy when the company implements a high transparency policy than when the company implements low outcome transparency. The highest tendency of managers to do FDRS bias is in a condition when there is low information accuracy with a high level of transparency. This is because managers will save personal costs by providing profitable differentiation for high-performing store managers. Thus, if a low-performing store manager confronts the regional manager, the cost of the contrast will be cheaper and the regional manager can retain the high-performing store manager.

Theoretically, this study answers suggestions from research by Bol et al. (2016) to use information accuracy and outcome transparency as an effort to reduce bias in FDRS. Also, this study provides a solution to minimize the existence of performance appraisal bias because there is still a lack of literature discuss it. Furthermore, this study adds to the insight about the application of FDRS in terms of rater because previous research is still few.

In practical terms, this research can be an input for companies to be able to implement control systems by increasing accuracy in the management accounting system so that middle managers can use this information as a basis for evaluating FDRS. Furthermore, this research can serve as a suggestion for companies to implement a control system to minimize bias in the form of a transparency policy on the results of the assessment ranking because not all companies implement this policy.

\section{Limitations and opportunities for further research}

This study used a web-based experimental method to examine the effect of information accuracy and outcome transparency on the bias of FDRS performance appraisal. Case material reflects a simplified abstraction from the actual FDRS and may not capture the FDRS variable in the real world. This is proven by the number of participants who did not pass manipulation as much as $23 \%$. This study uses the FDRS 20/20/20/20/20 distribution allocation to 5 store managers only. The use of FDRS can be applied to companies depending on the normal distri-bution curve in which the company has many employees so that these employees can distribute the FDRS allocation category that has been determined by the organization. Therefore, further research is suggested to be able to develop case scenarios that 
better reflect FDRS in the real world, such as assessing 20 store managers, so that the distribution of FDRS allocations such as those of General Electric 20/70/10 is applicable.

The use of undergraduate students as experimental participants may be potential limitations, so care is needed in generalizing the results of this study. Future studies can use middle managers as participants. Also, information regarding the accuracy of the information in this study was only developed by AbdelRahim \& Stevens, and Bol et al. so further studies are needed to explore the accuracy of the information contained in the management accounting system.

\section{Acknowledgment}

I thank Prof. Mahfud Sholihin, M. Acc., Ph.D. as my thesis supervisor, anonymous re-viewer team, and editor team of 1st ICEMAC Nusa Putra University, and all of 1st ICEMAC Nusa Putra University committees for the comments and suggestions. I also thank the account-ing students in Yogyakarta who have participated in this study.

\section{References}

Abdel-rahim, H. Y., \& Stevens, D. E. (2017). Information system precision and honesty in managerial reporting: A re-examination of information asymmetry effects. Accounting, Organizations and Society, 31-43. https://doi.org/10.1016/j.aos.2017.12.004

Adams, J. S. (1964). Inequity in social exchange. Advances in Experimental Social Psychology, 2, 267-299

Babbie, E. (2007). The basics of social research (4th ed.). USA: Thomson Wadsworth.

Bates, S. (2003). Forced Rangking. HR Magazine, 62-68.

Berger, J., Harbring, C., \& Sliwka, D. (2013). Performance appraisals and the impact of forced distribution - An experimental investigation. Management Science, 59(1), 54-68.

Blume, B. D., Rubin, R. S., \& Baldwin, T. T. (2013). Who is attracted to an organisation using a forced distribution performance management system?. Human Resource Management Journal, 23(4), 360-378. https://doi.org/10.1111/1748-8583.12016

Bol, J. C. (2011). The determinants and performance effects of managers' performance evaluation biases. The Accounting Review, 86(5), 15491575. https://doi.org/10.2308/accr-10099

Bol, J. C., Kramer, S., \& Maas, V. S. (2016). How control system design affects performance evaluation compression: The role of information accuracy and outcome transparency. Accounting, Organizations and Society, 51, 64-73. https://doi.org/10.1016/j.aos.2016.01.001

Bretz, R. D., Milkovich, G. T., \& Read, W. (1992). The current state of performance appraisal research and practice: Concerns, directions, and implications. Journal of Management, 18(2), 321-352.

Chattopadhayay, R., \& Ghosh, A. K. (2012). Performance appraisal based on a forced distribution system: Its drawbacks and remedies. International Journal of Productivity and Performance Management. https://doi.org/10.1108/17410401211277138

Christian, S. (2018). How relative performance information affects employee performance: A systematic review of empirical research. SSRN Electronic Journal. https://doi.org/doi 10.2139_ssrn.3327238

Evans, J. H., Moser, D. V., Newman, A. H., \& Stikeleather, B. R. (2012). Honor among thieves : Open internal reporting and managerial collusion. Contemporary Accounting Research, 33(4), 1375-1402

Festinger, L. (1954). A theory of social comparison processes. Human Relations,7(2), 47-56. https://doi.org/10.1177/001872675400700202

Giebe, T., \& Gürtler, O. (2012). Journal of economic behavior \& organization optimal contracts for lenient supervisors. Journal of Economic Behavior and Organization, 81(2), 403-420. https://doi.org/10.1016/j.jebo.2011.11.003

Golman, R., \& Bhatia, S. (2012). Performance evaluation inflation and compression. Accounting, Organizations and Society, 37, $534-543$. https://doi.org/10.1016/j.aos.2012.09.001

Harris, M. M. (1994). Rater motivation in the performance appraisal context : A theoretical framework. Journal of Management, 20(4), 737756.

Maas, V. S., Van Rinsum, M., \& Towry, K. L. (2012). In search of informed discretion: An experimental investigation of fairness and trust reciprocity. The Accounting Review, 87(2), 617-644. https://doi.org/10.2308/accr-10205

Malhotra, G., \& Mukherjee, A. (2013). Comparative study of forced distribution and absolute rating performance management systems. International Journal of Business Excellence, 6(2), 121-130. https://doi.org/10.1504/IJBEX.2013.052475

Moon, S. H., Scullen, S. E., \& Latham, G. P. (2016). Precarious curve ahead: The effects of forced distribution rating systems on job performance. Human Resource Management Review, 26(2), 166-179. https://doi.org/10.1016/j.hrmr.2015.12.002 
Mulligan, J. R., \& Bull Schaefer, R. A. (2011). A new hope for rank and yank. Journal of Leadership and Organizational Studies, 385-396. https://doi.org/10.1177/1548051811405206

Nahartyo, E. (2013). Desain dan implementasi riset riset eksperimen (2nd ed.). Jakarta: UPP STIM YKPN.

Schleicher, D. J., Bull, R. A., \& Green, S. G. (2009). Rater reactions to forced distribution rating systems. Journal of Management, 35(4), 899927. https://doi.org/10.1177/0149206307312514

Scullen, S. E., Bergey, P. K., \& Aiman-Smith, L. (2005). Forced distribution rating systems and the improvement of workforce potential: A baseline simulation. Personnel Psychology, 58(1), 1-32. https://doi.org/10.1111/j.1744-6570.2005.00361.x

Stewart, S. M., Gruys, M. L., \& Storm, M. (2010). Forced distribution performance evaluation systems: Advantages, disadvantages and keys to implementation. Journal of Management \& Organization, 16(1), 168-179. https://doi.org/10.1017/s1833367200002340

Zimmerman, J. L. (2000). Accounting for decision making and control (S. Mattson (ed.); 7th ed.). New Jersey: McGraw-Hill. 